\title{
RESEARCH WORK CONCERNING THE CONCEPTION AND IMPLEMENTATION OF MECHATRONIC AND ADAPTRONIC AND CYBER-MECATRONIC AND CYBER-ADAPTRONIC VIRTUAL AND PHYSICAL MODELS
}

\author{
Gheorghe I. Gheorghe ${ }^{1}$, Iulian Ilie ${ }^{2}$ \\ ${ }^{1,2}$ National Institute of Research and Development in Mechatronics \\ and Measurement Technique, Bucharest \\ geocefin@yahoo.com
}

\begin{abstract}
The scientific work synthesizes the realization and testing of experimental mechatronic and adaptronic \& cyber-mechatronic and cyber-adaptronic experimental models based on the development of new scientific and technological concepts and new virtual models of smart systems in original constructive solutions of the authors in order to implement them in the industry and in laboratories.
\end{abstract}

Keywords: Mechatronic and Adaptronic Experimental Model; Smart Cyber-Mechatronic and Cyber-Adaptronic Domains; Advanced Scientific and Technological Concept.

\section{Introduction}

\section{Main objectives:}

- development of new solutions for virtual models and configurations of mechatronic and adaptronic and cyber-mechatronic and cyberadaptronic models and experimental models for the industry and laboratories;

- development of concepts of new constructive solutions for such smart systems;

- creation and development of smart smart control technologies integrated into smart systems;

- improvements in technical and technological performance of smart mechatronic and adaptronic and cyber-mechatronic and respectively cyberadaptive smart systems;

- integration of virtual concepts into the modelling of new solutions of mechatronic and adaptive and cyber-mechatronic and cyberadaptronic systems;

- development of smart applications for smart fields such as:

$>$ aerospace;

$>$ machine tools - CNC tools;

$>$ field of equipment / complex systems with powerful lasers;

$>$ smart agriculture (agriculture 4.0);

$>$ smart industry (industry 4.0);

$>$ medical and biomedical field;

$>$ etc.

- development of the capability of the mechatronics and cyber-mechatronics industry with the approach of multidisciplinarity and interdisciplinarity;

- development of dynamic and control systems engineering;

- development of distributed and competing interactions in mechatronic and cyber-mechatronic systems;

- development of emerging behaviour and reconfiguration capacity;

- development of a new methodology for understanding the interactions of physical/mechatronic systems with virtual systems (Internet, Intranet, etc.);

- development of compositional theory for "plug and play" module integration;

- full development of data provision and its circulation in smart systems;

- development of smart mechatronic and adaptive and cyber-mechatronic and cyber-adaptive smart systems, with industrial applications:

$>$ in the automotive industry;

$>$ in the mechatronics industry;

$>$ in the medical and biomedical industry;

$>$ etc.

- development of special and specialized software for mechatronic and adaptronic and cybermechatronic and cyber-adaptive systems, with the following computer modules:

$>$ pre-processing;

$>$ signal conditioning;

$>$ data mining facilities;

$>$ defect detection; 
$>$ recalibration / reconfiguration;

$>$ final decisions;

$>$ etc.

- developing dedicated software for:

$>$ teleservice;

$>$ telemonitoring;

$>$ remote control;

$>$ teleconfiguration;

$>$ telemaintenace;

$>$ etc.

- development of architectural schemes of smart systems:

$>$ the smart system itself;

$>$ the cyber space system;

$>$ remote control centre and telecontrol system.

\section{Specific objectives}

- study and analysis of the conceptions of the mechatronics and adaptive and cyber-mechatronics and cyber-adaptive industrial and laboratory models;

- development of new scientific and technological concepts for industrial and laboratory cycles of mechatronics and adaptronics, respectively cybermechatronics and cyber-adaptronics;

- making and testing experimental mechatronic and adaptronic experimental and cyber-mechatronic and cyber-adaptronic respectively for industry and laboratory;

- dissemination of new knowledge and information on the project and the experimental model mechatronic and adaptronic, respectively cybermechatronic and cyber-adaptronic;

-experimental model preparation for demonstration at the beneficiary.

\section{Structure of the experimental model}

$>$ the mechanical anti-vibration table subsystem (Figure 1), which provides vibration-free conditions, even where they are, "horizontally plane" conditions in ultra-precise tolerances and mechanical clamping conditions of the "mecatronic smart and adaptronic and cyber-mecatronic smart cyber-adaptronic "

$>$ "Integrated body" mechanical subsystem, which secures other elements: sensor space barriers for "measuring space" security, TV cameras for image reproduction of the entire mecatronic smart system and adaptronic and cyber-mecatronic and cyber-adaptronic; the control and command module and other reference elements for the electrical wiring of the sub-systems.

- The Integrated Body Subsystem also includes transparent plastic plate markers that configure the total working space of the smart system;
$>$ experimental model: mecatronic and adaptronic and cyber-mecatronic and cyberadaptronic systems, with the following structure:

- "X-axis" subsystem, nominal stroke of $200 \mathrm{~mm} /$ length (gauge); axis $510 \mathrm{~mm}$, nominal force of $205 \mathrm{~N}$ (maximum force - 500N); 1 linear motor; 1 encoder absolute transducer with precision repeatability; 1 controller;

- "Y axis" subsystem, nominal stroke of $100 \mathrm{~mm}$ / length (gauge); axis $310 \mathrm{~mm}$, nominal force $120 \mathrm{~N}$ (maximum force - 250N); 1 linear motor; 1 encoder absolute transducer with precision repeatability; 1 controller;

"Z axis" subsystem, nominal stroke of $100 \mathrm{~mm} /$ length (gauge); axis $310 \mathrm{~mm}$, nominal force; 1 linear motor; 1 encoder absolute transducer with precision repeatability; 1 controller;

- miniature rotary drive subsystem with 1 controller;

•"electric gripper" subsystem with 1 controller;

- "microgripper" subsystem, which integrates into the smart system and ensures the "handling of small parts and microwaves" in 4D (3 cartesian axes + 1 rotation axis) and the fitting of the smart touch probe in 3D for the integrated measurement and control process;

$>$ "Smart 3D Touch Probe" subsystem for the integrated measurement and control process;

$>$ "Sensory barriers" subsystem to ensure work area security (4D measurement);

$>$ "Interface" subsystem for the 4D and cyberspace smart system;

$>$ "Signal cable" subsystem 4D system command and control model;

$>$ "Control panel" subsystem with PLC and 4D system software;

$>$ "GPRS4G modem" subsystem;

$>$ "Antenna" subsystem;

$>$ WAN internet connection router subsystem;

$>$ "PC monitor" subsystem;

$>$ "Central unit" subsystem;

$>$ "Telecontrol and telemonitoring software" subsystem.

\section{Presentation and description of the experimental model}

Based on the original concepts of virtual models designed by new and innovative constructive solutions and based on the scientific and technological concepts for new mechatronic and adaptive and cyber-mechatronic models and cyberadaptive virtual models, we have proceeded to the realization and testing of the experimental model mecatronic and adaptronic and cyber -mechatronic and cyber-adaptronic for industry and laboratory, as follows: 


\section{(4.1) Design and physical realization of the}

"anti-vibration table" subsystem to provide vibration free support for the mecatronic and adaptronic and cyber-mecatronic and cyberadaptronic experimental model.

The structure of the subsystem (Figure 1) contains:

$>$ work table;

$>$ self-levelling (flat horizontal) microsystem;

$>$ mechanical body;

$>$ casters (for displacement);

$>$ adjustable support;

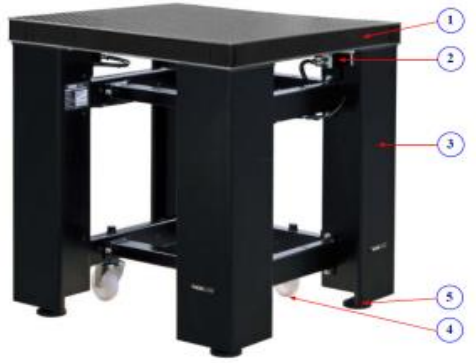

Legend: 1-work table:

2-self-leveling mechanism

3-mechanical body;

4-casters (for displacement)

5-adjustable support;
Constructive solutions adopted for the "antivibration table subsystem" include:

- correct positioning of the body (as in fig. 2);

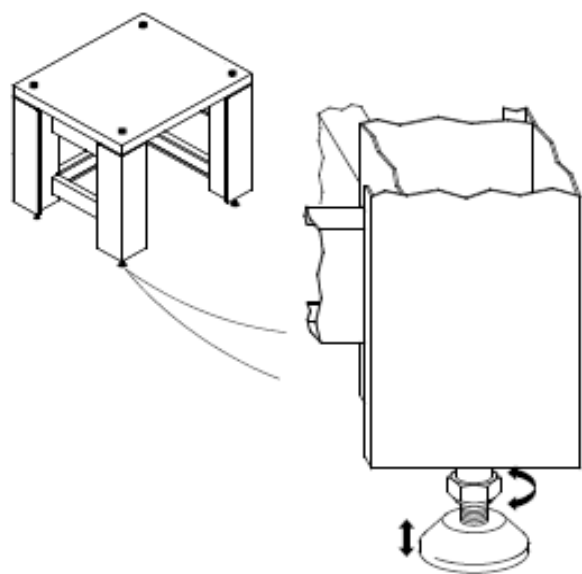

Figure 2: Correct positioning of the body

- air supply connections of the pneumatic installation for the anti-vibration table (as in fig. 3);

Figure 1: Anti-vibration table subsystem

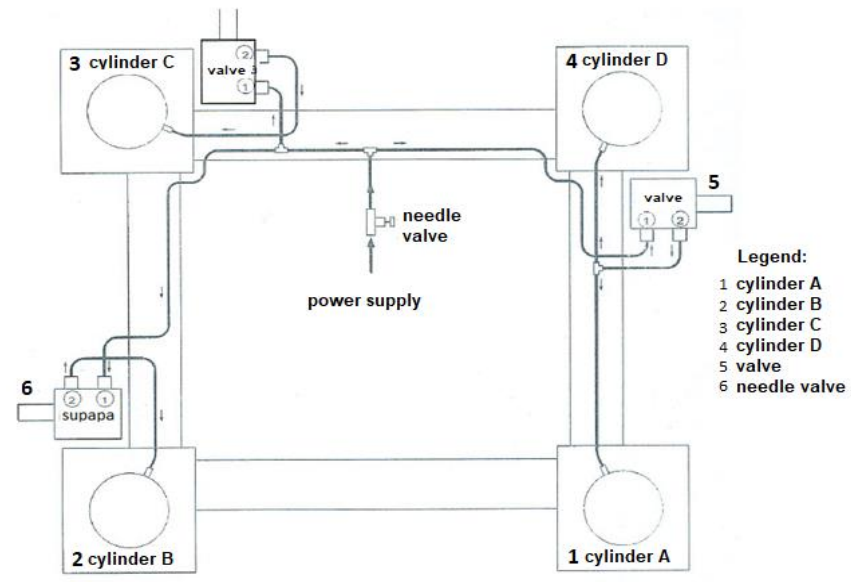

Figure 3: Air supply connections of the pneumatic installation for the anti-vibration table

- Self-levelling mechanism with height adjustment system (controlled by lifting / lowering and handling bushings) (as in fig. 4);

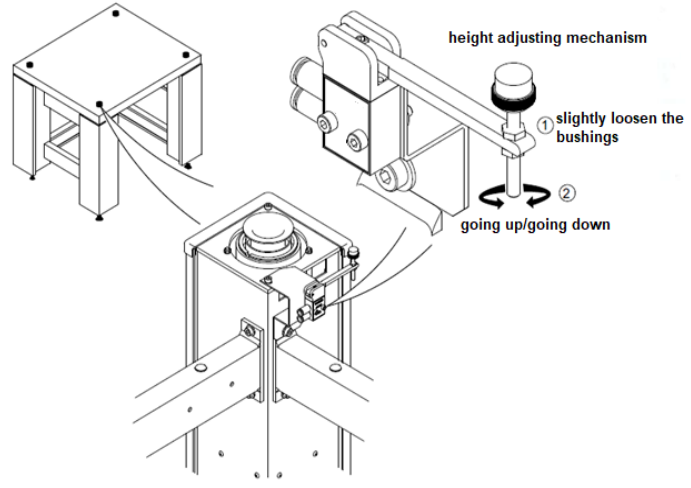

Figure 4: Self-levelling mechanism 


\section{(4.2) The conception and physical realization of the experimental model: "mecatronic and adaptronic \& cyber- mecatronic \& cyber-adaptronic system"}

At the basis of the execution of the experimental model "mecatronic and adaptronic \& cyber- mecatronic \& cyber-adaptronic system" was the original conception of the logic scheme - mecatronic and adaptronic \& cyber-mecatronic \& cyberadaptronic system (Figure 6) and the orthogonal projection of the experimental model with the component structure of the X, Y, Z and $\Phi$ subsystems.

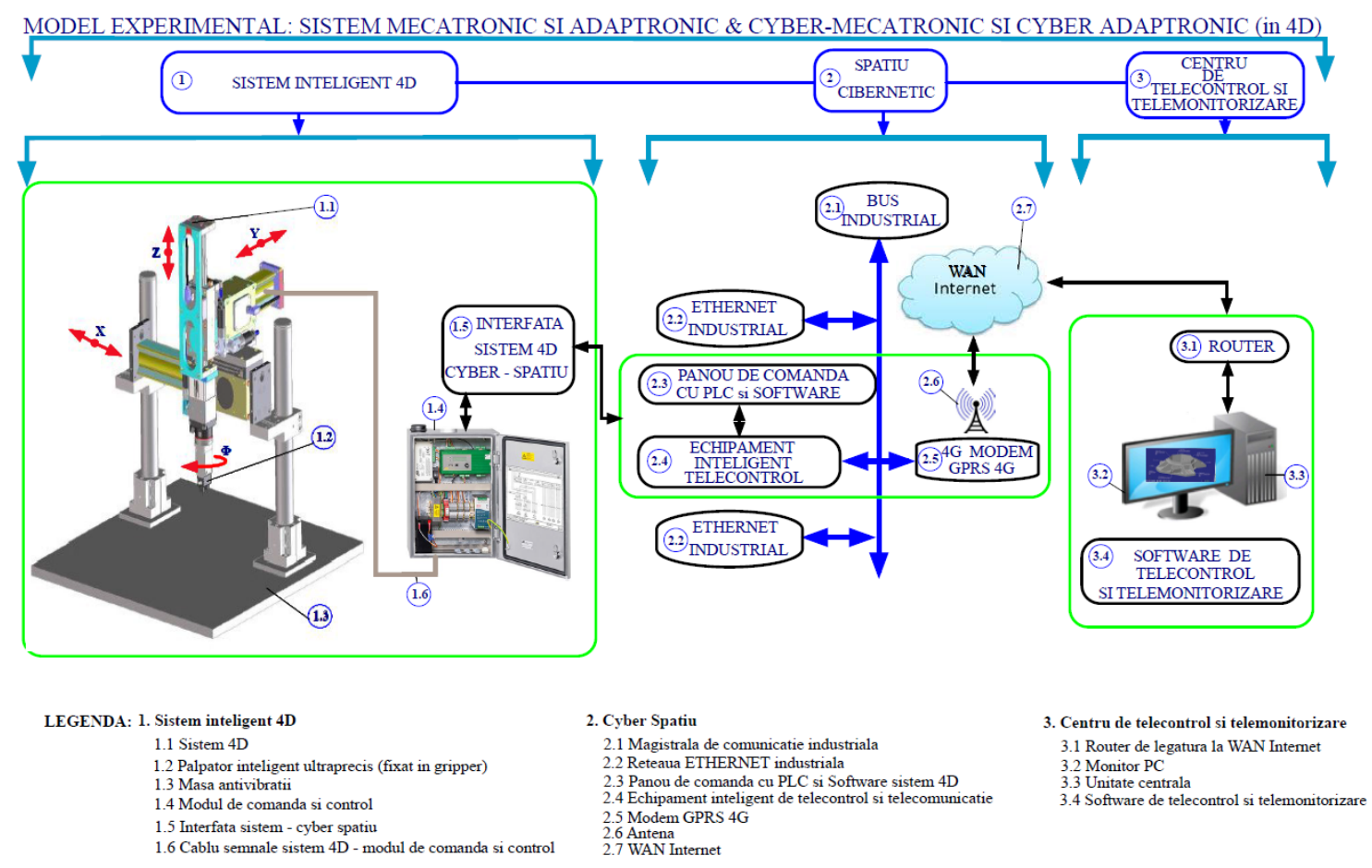

Figure 5: Logic scheme - Mecatronic and adaptronic \& cyber-mecatronic \& cyber-adaptronic system

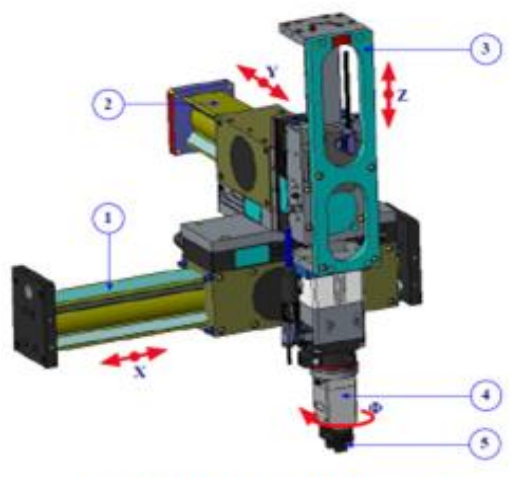

Legend: 1 - X electrical axis 2 - Y electrical axis 3 - Z electrical axis 4 - electrical axis 5 - Gripper

Figure 6: Mecatronic and adaptronic \& cybermecatronic \& cyber-adaptronic system

Following is presented the experimental model "Mechatronic and adaptronic \& cyber-mecatronic and cyber-adaptronic system in 4D coordinates (fig. 7)".

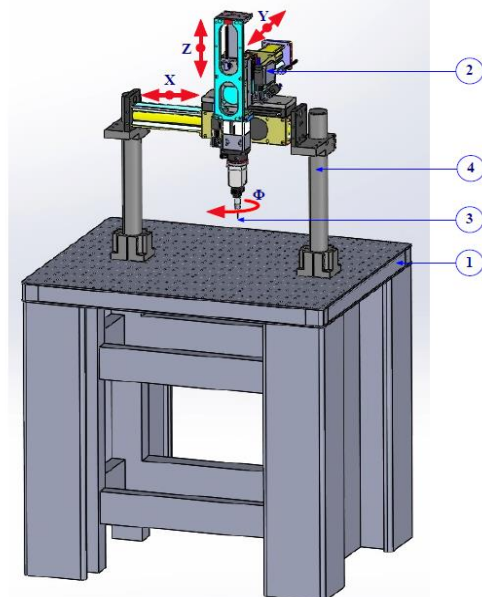

Legend:

1 - Anti-vibration table

2 - Smart system (in 4D)

3 - Smart (ultraprecise) 3D probe

4 - Adjustable support

Figure 7: Mechatronic and adaptronic \& cybermechatronic and cyber-adaptronic system in $4 D$ 
Following is presented the experimental model "Mechatronic and adaptronic \& cyber-mecatronic and cyber-adaptronic system in 4D coordinates" below (fig. 8):

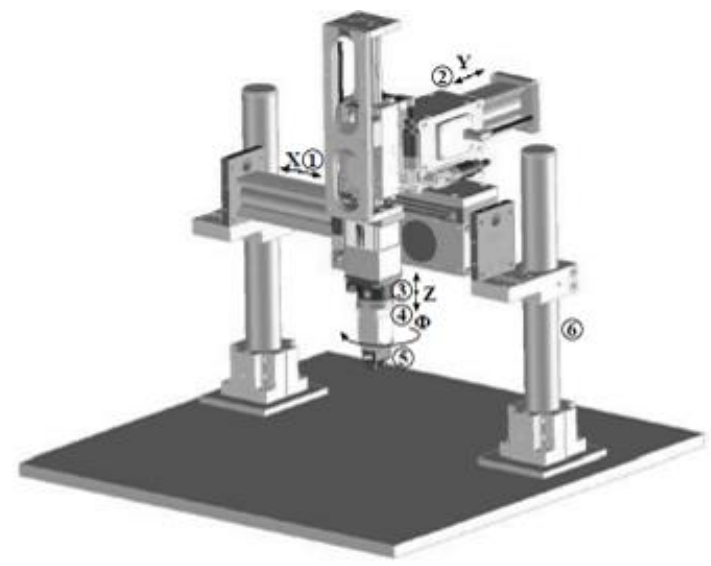

Legend: 1 - $X$ electrical axis

2 - Y electrical axis

3 - Z electrical axis

4 - 9 electrical axis

5 - Gripper

6 - Adjustable support

Figure 8: Experimental model - "Mechatronic and adaptronic \& cyber-mecatronic and cyber-adaptronic system in $4 D$ coordinates" (without the anti-vibration table and the smart $3 D$ probe)

According to this figure, the experimental model made consists of:

- Horizontal electric axis X: carried out in a structure defined by the nominal stroke (measuring range) of $200 \mathrm{~mm}$ and the gauge of the axis $510 \mathrm{~mm}$ by the nominal force of $205 \mathrm{~N}$ (and the maximum permissible force of $500 \mathrm{~N}$ ), by 1 linear motor, 1 absolute encoded transducer with high precision and repeatability, 1 controller;

- Horizontal electric axis Y: carried out in a structure defined by the nominal stroke (measuring range) of $100 \mathrm{~mm}$ and a gauge length of $310 \mathrm{~mm}$, by a nominal force of $120 \mathrm{~N}$ (and the maximum permissible force of $250 \mathrm{~N}$ ) by 1 linear motor, 1 absolute encoded transducer with high precision and repeatability, 1 controller;

- vertical $\mathrm{Z}$ axis: made in a structure defined by the nominal stroke (measuring range) of $100 \mathrm{~mm}$, a nominal force of $115 \mathrm{~N}$ (max.), 1 linear motor, 1 brake, 1 encoded absolute encoder, with high precision and repeatability, 1 controller;

- the rotary (miniaturized) electric axis and 1 controller (figure 14): made in a structure defined by:

$>$ torque: 0.4 / $1.2(\mathrm{Nm})$;

$>$ maximum rotation speed: 600 (1/ min.);

$>$ moment of inertia: 500 (Kgmm2);
$>$ repeatability accuracy: $0.01\left(^{\circ}\right)$;

$>$ operating pressure: 6 (bar);

> meat: $1.2(\mathrm{Kg})$;

$>$ temperature: $10 / 40\left({ }^{\circ} \mathrm{C}\right)$;

$>$ circuit voltage: $530(\mathrm{~V})$;

$>$ power supply: 1 (A);

$>$ electronic control: external;

> encoder system: absolute encoder.

The representation of the rotating unit is given in Figure 9, according to the partial longitudinal section:

(1) engine;

(2) absolute encoder;

(3) primary gripping part;

(4) secondary component;

(5) power supply;

(6) body;

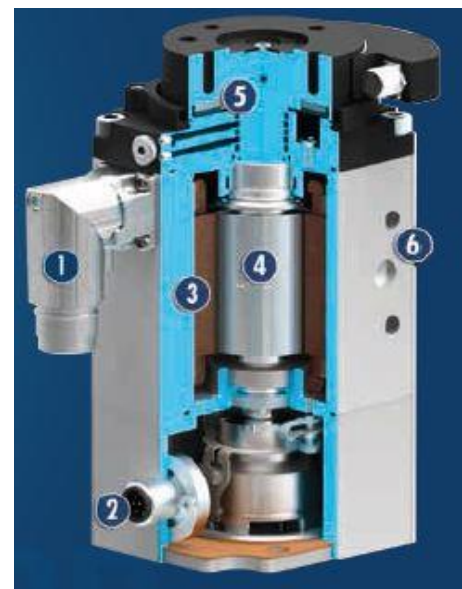

Figure 9: Longitudinal section of the rotary unit

Figure 10 shows the "rotating unit" (1) integrated in the original design solution with the "electric $\mathrm{Z}$ axis" (2) and the parallel gripper (3) for gripping the parts and for manipulating and positioning them.

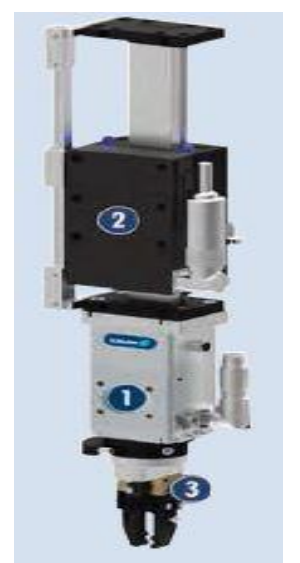

Figure 10: Z-axis integrated with rotating unit and parallel gripper 
- The parallel gripper is designed for manipulating and positioning small and miniaturized parts and for 3D touch probe grip (Figure 11) with the following features:
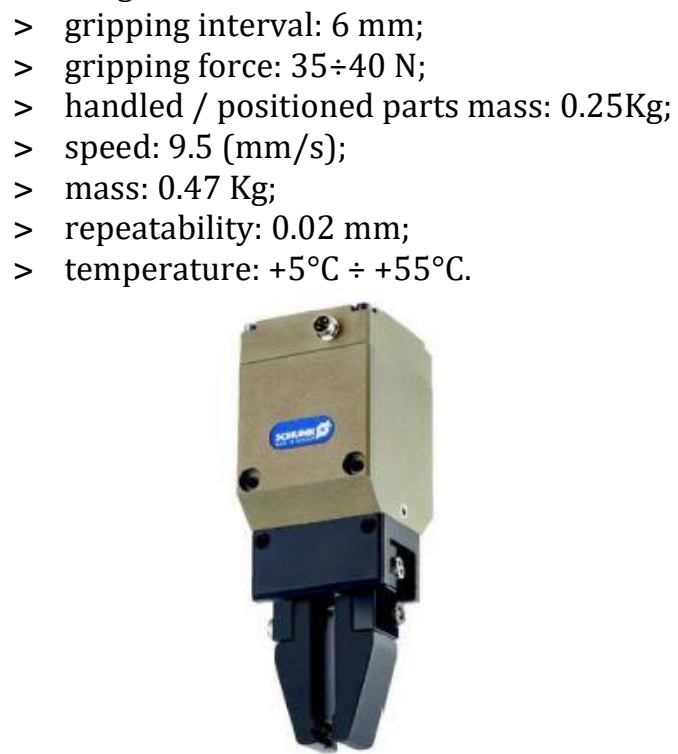

Figure 11: Parallel gripper

- $\quad$ The ultra-precision 3D probe (Figure 12) is designed for measuring and controlling small and medium-sized industrial parts. Integration of the 3D touch probe is made by the technological attachment in the parallel gripper, the touch probe being connected to its own electronic module with a microcontroller and its own electronic communication module with mechatronic and adaptronic \& cyber-mechatronic and cyberadaptronic system.

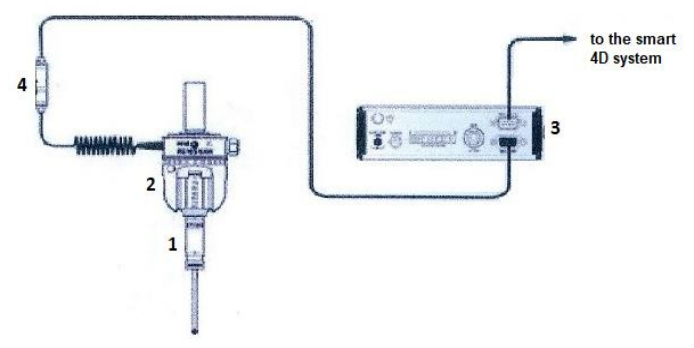

Legend:

$1-3$ D probe;

2 - automatic fasting subsystem;

3 - electronic module with micro-controller;

4 - connection cable.

Figure 12: Ultra-precision 3D probe with microcontroller in its structural logic diagram

(4.3) The conception and physical realization of the "Integrated body" subsystem (Figure 13) to ensure and secure the workspace for the experimental model - mecatronic and adaptronic \& cyber-mecatronic and cyber-adaptronic system.

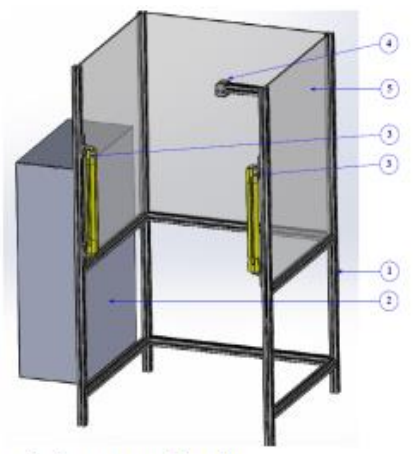

Legend: 1 -structural body

2 - command and control module

3 - sensoristic barriers

4 - IP camera

5 - transparent plastic protective walls for securing the workspace

Figure 13: Integrated body (for the smart 4D system)

The structure of the "integrated body" sub-assembly has the following components:

$>$ body structure (made of profile 45X45 duralumin), (1);

$>$ control and control module (item 2) made of special electronic components suitable for the $4 \mathrm{D}$ smart system: programmable PLCs, GPRS 4G communication modem, power supply (Figure 14);

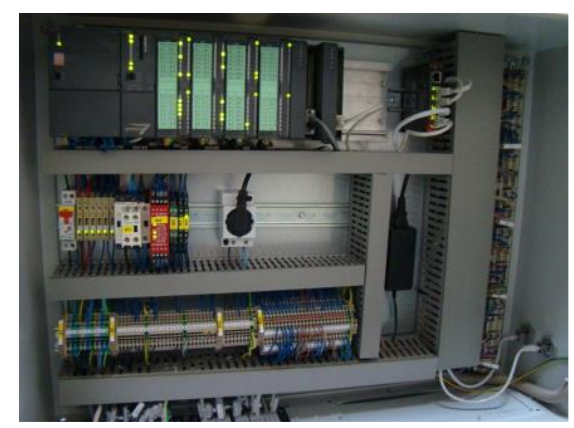

Figure 14: Internal view of the command and control mode

$>$ sensory barriers (made from sensory mechatronic structures), (3), (fig. 15);

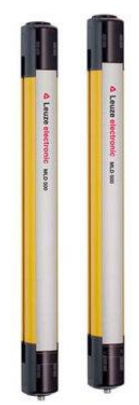

Figure 15: Optical sensory barriers

$>$ IP camera (designed to visualize the smart 4D system in its industrial application), (4), (fig. 16); 


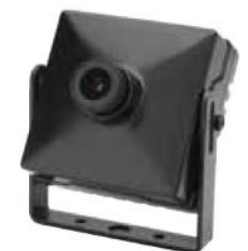

Figure 16: IP miniature Micro-digital camera - MDCN3290FDN

$>$ Protective walls for securing the working space of the smart 4D system, (5) made of transparent plastic;

\section{(4.4) The conception and physical} realization of the "Smart 4D Smart System Interface - Cyber Space (item 1.5)", based on special electronic components and appropriate to the links and connections between the smart 4D system and the cyber space;

(4.5) The conception and physical realization of the configuration of the "cyber space" (item 2.2) based on the following special components:

$>$ the industrial communications bus (item 2.1);

$>$ the industrial ETHERNET network (at the industrial application site and with the beneficiary's agreement) (item 2.2);

$>$ control panel with PLC and 4D system software (item 2.3), structured on PLCs and special software;

$>$ smart telecontrol and telecommunication equipment (item 2.4), structured on specific communication modules (WIFI, ETHERNET, ZEEGBEE);

> GPRS 4G modem (item 2.5), (data transmission over the mobile network);

$>$ antenna (item 2.6);

$>$ WAN Internet (item 2.7), (the global Internet network);

(4.6) The conception and physical realization of the configuration of the "telecontrol and telemonitoring centre" (item

2.3) based on the special electronic and computing components:

$>$ WAN Internet connection router (item 3.1) (Figure 17);

$>$ PC monitor (item 3.2);

$>$ central unit (item 3.3);

$>$ telecontrol and telemonitoring software (item 3.4);

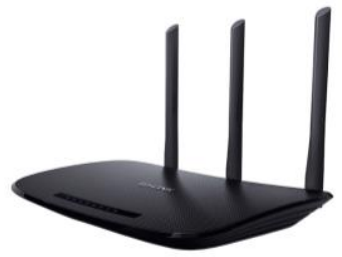

Figure 17: 4G Router - 7305-N66U Asus RT-N66U
(4.7) The physical realization of the model of the mecatronic and adaptronic and cybermecatronic and cyber-adaptronic systems continued with testing of the experimental model achieved in the project.

A test program with prescribed values of the main subsystems and smart 4D system has been developed, as follows:

(4.7.1) functional testing of the ultra-precision 3D touch probe (Figure 18) by checking the metrological performance within the Metrology Laboratory, RENAR certified, consisting of:

(4.7.1.1) testing of the measuring range: verified by using the "Optimes" nanometre measuring device (10 nanometres) by attaching the 3D touch probe to the instrument and conducting the metrological displacement for its measuring range: $\mathrm{x}= \pm 2 \mathrm{~mm} ; \mathrm{y}= \pm 2 \mathrm{~mm} ; \mathrm{z}= \pm 2,5 \mathrm{~mm}$, the result obtained: according to the metrological data from the test program and from the catalogues of some companies (Renishaw - England, MitutoyoJapan);

(4.7.1.2) repeatability test: Verified on the same Optime apparatus with more than 100 probing cycles resulting in a repeatability error of $\pm 0,0004$ $\mathrm{mm}$ maximum, over the maximum error recorded in the test program and in different catalogues by companies of $\pm 0,00045 \mathrm{~mm}$, the result obtained: according to the test program data and international catalogues;

(4.7.1.3) testing of the measuring force: checked on a small force measuring instrument (up to $30 \mathrm{CN}$ ), existing in the Metrology Laboratory, resulting in an average value of approx. $25 \mathrm{CN}$, the result obtained: according to test program data and international catalogues;

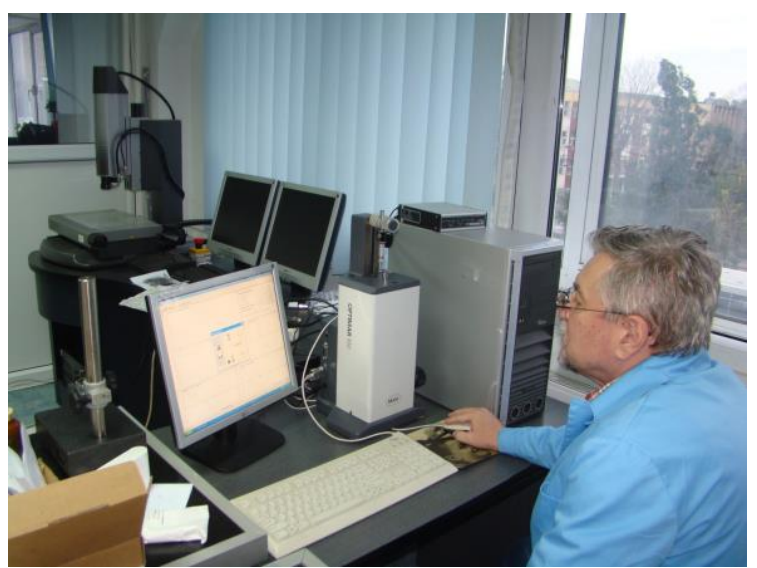

Figure 18: 3D probe testing

(4.7.2) functional testing of the parallel gripper by verification of metrological performances in the Metrology Laboratory, RENAR certificates, consisting of: 
(4.7.2.1) testing of the 6-mm gripping interval: checked by opening the fingers to the limit and measured with a $0.01 \mathrm{~mm}$ digital type digital instrumentation instrument; the measurement result was $6 \mathrm{~mm} \pm 0.015 \mathrm{~mm}$, corresponding to the data from the Schunk-Germany catalogue; the result obtained: according to company catalogue data;

(4.7.2.2) testing of the 35 to $40 \mathrm{~N}$ preloading gripping force: Check the clamping force on different metallic and non-metallic parts (e.g. thermos-digital plastic) by means of metrological calibrated force and torque transducers to obtain after 30 checks, tightening torque values and average values of $35.5 \div 38.5 \mathrm{~N}$ are included in the test program data and company catalogues (Schunk, etc.), the result obtained: according to with the test program data and the catalogues of international firms;

Note: the weight of the tested parts generally ranged from $0.20 \div 0.24 \mathrm{~kg}$, corresponding to the recommendations of the test program;

(4.7.2.3) testing of the gripper mass of $0.46 \mathbf{~ k g}$ : the gripper mass has been checked with an analytical balance of $\pm 2 \mathrm{~g}$ precision, resulting in a mass of about $0.450 \mathrm{~kg}$, the result obtained: according to the program data testing and catalogues of international companies;

(4.7.2.4) repeatability testing of $\mathbf{0 . 0 2} \mathbf{~ m m}$ : over 40 shoulder straps have been checked by means of tensiometric marks transducers, checking the repeatability of the tightening in the dimensional variation and obtaining values ranging from $0.015 \div$ $0,018 \mathrm{~mm}$, the result obtained: according to the test program data and international company catalogues;

(4.7.3) functional testing of the electric axes $x$, $\mathrm{y}$ and $\mathrm{z}$ for:

(4.7.3.1) testing the measuring range of the electric axes $x, y$ and $z$ (Figure 19):

(a) for $x=200 \mathbf{m m}$ : verified by a $3 \mathrm{D}$ machine with an accuracy of $\pm 0.1 \mu \mathrm{m}$, averaged over $\mathrm{x}$ for 30 tests, with the value of $200 \mathrm{~mm} \pm 0,4 \mu \mathrm{m}$; the result obtained: according to the test program data and international catalogues;

(b) for $\mathbf{y}=\mathbf{1 0 0} \mathbf{~ m m}$ : verified by a 3D machine with an accuracy of $\pm 0.1 \mu \mathrm{m}$, averaged over y for 30 tests, with the value of $100 \mathrm{~mm} \pm 0,35 \mu \mathrm{m}$; the result obtained: according to the test program data and international catalogues;

(c) for $\mathbf{z}=\mathbf{1 0 0} \mathbf{~ m m}$ : verified by a 3D machine with an accuracy of $\pm 0.1 \mu \mathrm{m}$, averaged over $\mathrm{z}$ for 30 tests, with the value of $100 \mathrm{~mm} \pm 0,3 \mu \mathrm{m}$; the result obtained: according to the test program data and international catalogues;

The result obtained for the three axes $x, y$, and $\mathrm{z}$ : according to the test program data and international company catalogues.

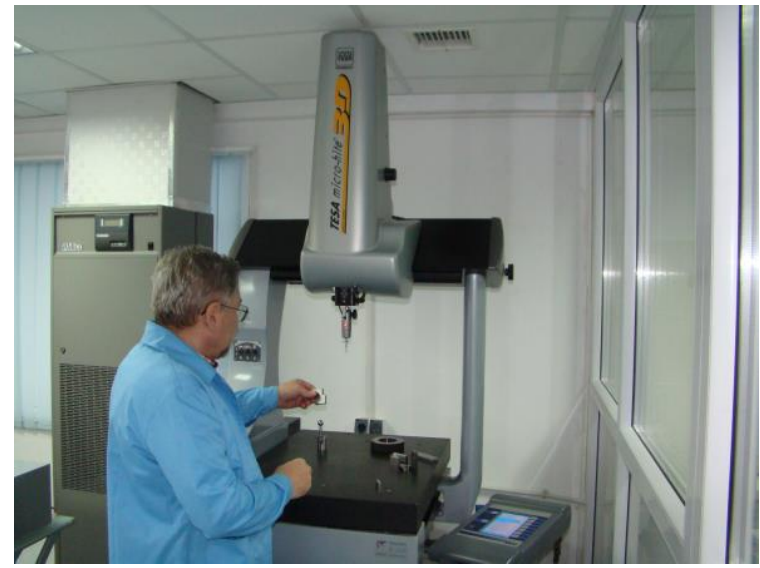

Figure 19: Experimental testing on a 3D machine

(4.7.3.2) testing of the measurement range of the axis $\varphi=360^{\circ}$ : checked with an incremental rotary photoelectric system mounted on the "rotating unit", reading the rotation angle of the rotating unit directly on the "electric block with digital display "in angular units, obtaining $\varphi=360 \pm$ 10 seconds: the result obtained: according to the test program data and the catalogues of foreign firms;

(4.7.3.3) precision error testing of electrical axes $x, y$, and $z$ :

(a) for axis $\mathbf{x}=\mathbf{2 0 0} \mathbf{~ m m}$ : checked with a 3D machine, with an accuracy of $\pm 0,1 \mu \mathrm{m}$, precision of the $\mathrm{x}$-axis over the $200-\mathrm{mm}$ measuring range, measurements at several measuring points distributed throughout the range, the precision error of $\pm 0.25 \mu \mathrm{m} / 200 \mathrm{~mm}$; the result obtained: according to the test program data and the catalogues of international companies;

(b) for the y axis $=100 \mathrm{~mm}$ : it has been verified with a 3D machine, with an accuracy of $\pm 0,1 \mu \mathrm{m}$, the precision of the $y$ axis on the $100-\mathrm{mm}$ measuring range, measurements at several measuring points distributed throughout the range, the precision error of $\pm 0,15 \mu \mathrm{m} / 100 \mathrm{~mm}$; the result obtained: according to the test program data and the catalogues of international companies;

(c) for the $\mathrm{z}$ axis $=100 \mathrm{~mm}$ : it has been verified with a 3D machine with an accuracy of $\pm 0,1 \mu \mathrm{m}$, the accuracy of the z-axis over the $100-\mathrm{mm}$ measuring range, measurements at several measuring points distributed throughout the range, the precision error of $\pm 0.18 \mu \mathrm{m} / 100 \mathrm{~mm}$; the result obtained: according to the test program data and the catalogues of international companies;

(4.7.3.4) testing the precision of the rotating unit $\varphi$ :

for $\varphi=360^{\circ} \mathrm{C}$ of the rotating unit: it was checked with the incremental rotary photoelectric transducer (with 500 pulses / rotation) by mounting it on the rotating unit, measured in more than 20 angles per $360^{\circ}$, the rotational error and obtaining an average value of \pm 0.1 degree $/ 360^{\circ}$; the result obtained: 
according to the test program data and the catalogues of international companies;

(4.7.3.5) functional testing of the 4D smartphone interface - cybernetic space was performed by verifying the connection of the control and control module (1.4) to the Internet (2.7) by using a "ASUS N-750 Laptop Model" - a browser response time by executing the ping command at the IP address assigned to the command and control module, obtaining response time values in the range of $2 \div$ $10 \mathrm{~ms}$ (milliseconds); the result obtained: is in accordance with the requirements of telecontrol and telemonitoring applications (less than $50 \mathrm{~ms}$ );

(4.7.3.6) functional testing (and initialization) of the router of the telecontrol and telemonitoring centre was done in two stages:

(a) testing the Internet connection through the router, of the central PC unit, using current applications (Google), achieving the maximum data transfer speed of $80 \mathrm{MB} / \mathrm{s}$ (according to www.testspeed.com); the result obtained: complies with the specifications of the fibre-optic Internet connection of the INCDMTM central server;

(b) testing the secure VPN connection with the 4D smart system, using the specially developed software; the remote control of the main control functions (displacements on the 4 axes - $x, y, z, \varphi$ ) was tested; viewing the IP camera signal; Security warnings from sensory barriers; the result obtained: is in line with the purpose of the cyber-mecatronic and cyber-adaptronic concept and represents an original basis for the future development of cybermixmechronics systems.

(4.8) testing the operation of the mecatronic and adaptronic and cyber-mecatronic and cyberadaptronic experimental model assemblies, following the following phases:

(4.8.1) the anti-vibration table subsystem shall be fed to an instrument mass pressure of not more than 4 bar through the associated pneumatic installation (see Figure 1, Figure 2);

(4.8.2) the work table (position 1, figure 1) is positioned and balanced, the self-levelling mechanism is activated (Figure 4), the whole subsystem is correctly positioned;

(4.8.3) the smart $4 \mathrm{D}$ system (Figure 7, item 2) is positioned on the antivibration table (Figure 7, Item 1);

(4.8.4) the 3D (ultraprecis) smart gripper is engaged in the parallel gripper (figure 6, item 5) on the $\mathrm{z}$ axis (item 3 , figure 6 ) and is electrically coupled through its microcontroller smart 4D (item 2, figure 7);

(4.8.5) the 4D smart experimental model is powered at $380 \mathrm{~V}$ (industry specific);

(4.8.6) is powered by the control and control module (item 1.4, figure 5) through the 4D system cybernetic space (item 1.5, fig.5);
(4.8.7) the measurement data is collected by the 3D smart touch probe and processed by the measuring software itself, in the control and control module (item 1.4, figure 5);

(4.8.8) the data of the measurement process is transmitted via the $4 \mathrm{D}$ system - cybernetic space (item 1.5, fig.5) to the bus (item 2.1, fig.5) via industrial Ethernet (item 2.2, fig. 5) and control panel with PLC and specialized software (item 2.3, fig.5), via GPRS modem 4G (item 2.5, figure 5), via an antenna item 2.6, figure 5) and via WAN Internet 2.7, Figure 5).

(4.8.9) by the telecontrol and the telementenance centre (item 3, Figure 5), is ensured the visible connection on the PC monitor (item 3.2, Figure 5) via the router (item 3.1, fig.5) and of the telecontrol and telemonitoring software (item 3.4, fig.5) with the smart 4D system, through the Internet-Ethernet or telephony network, performing in real time all the activities specific to the measurement / control process, respectively telemetering / telecontrol and monitoring process, respectively telemonitoring with the operator smart $4 \mathrm{D}$ system to fit it into the real-time measurement / control / telemetry / telecontrol system.

(4.8.10) the whole procedure was enforced for the process of measuring / controlling cybernetics, experimenting with the telecontrol and telementenence process and extracting image capture, referring to the smart 4D system in operation, to the values and data collected by the system's sensory architecture, user mode telecontrol and telemonitoring software, how to enter orders, etc.

Here is an example:

- "the Interface" subsystem, contains other subsystems for analogue inputs, analogue outputs, numeric inputs / outputs, time interval generators, Sensory acquisition board 626 model, etc.

- the data measurement and processing software subsystem performs the following functions: provides a graphical interface for inputting and extracting measurement-specific data; allows configuration specific to each measurement (input parameters, working speed, rated values, tolerance limits, numerical and graphical display, etc.); purchase of data from electric axes $\mathrm{x}, \mathrm{y}, \mathrm{z}$ and $\varphi$ and from digital sensors, automated measurement; processes the data received during processing and issues the verdict / process decision; issues the final measurement report in numerical and graphic form, on screen and on paper.

- the user interface - monitoring software subsystem, presents the "frame window" with the display data as follows:

$>$ Input monitoring areas (1);

$>$ Output monitoring areas (2);

$>$ Command confirmation button (3);

$>$ Complementary output monitoring area (4); 
Research Work Concerning the Conception and Implementation of Mechatronic and Adaptronic and CyberMecatronic and Cyber-Adaptronic Virtual and Physical Models

Parameter entry areas command $1(5)$

Parameter entry areas command 1 (6);
Parameter entry areas command $1(7)$;

$>$ Comment entry area (8).

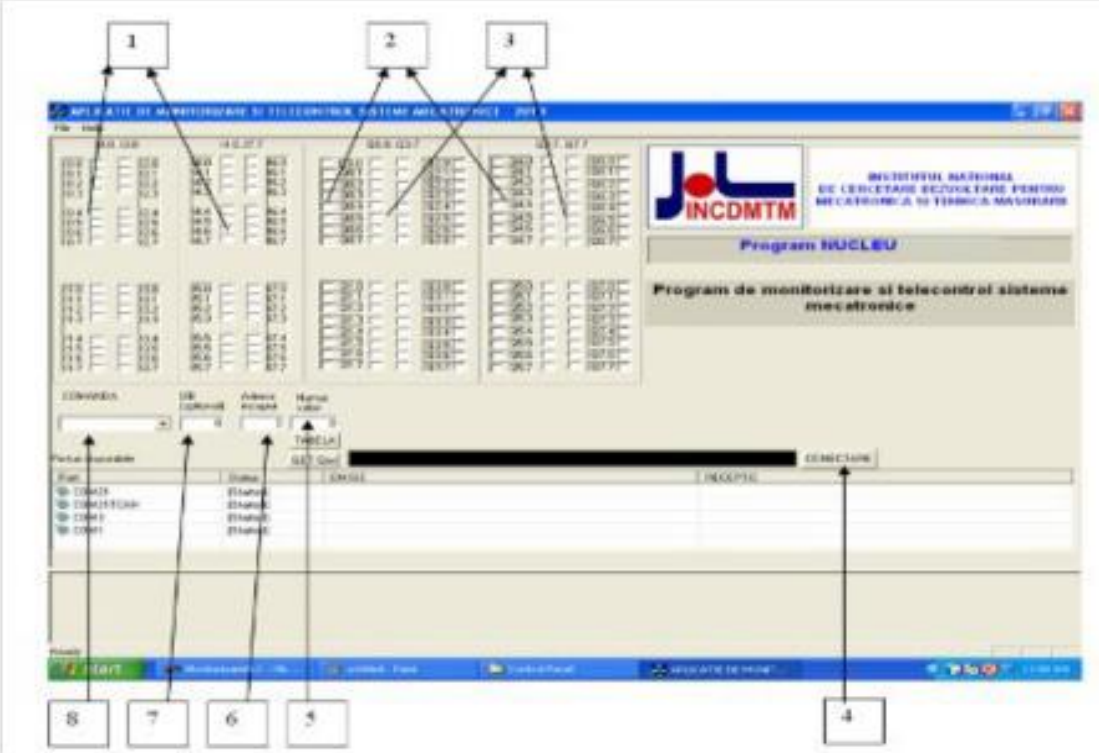

1. Input monitoring areas;

2. Output monitoring areas (2);

3. Command confirmation button (3);

4. Complementary output monitoring area (4);

5. Parameter entry areas command $1(5)$;

6. Parameter entry areas command 1 (6);

7. Parameter entry areas command 1 (7);

8. Comment entry area (8).

- user interface during operation subsystem, presents the "4D Smart System Monitoring and Remote-Control Program Window" with digital display parameters for telemonitoring and telecontrol.

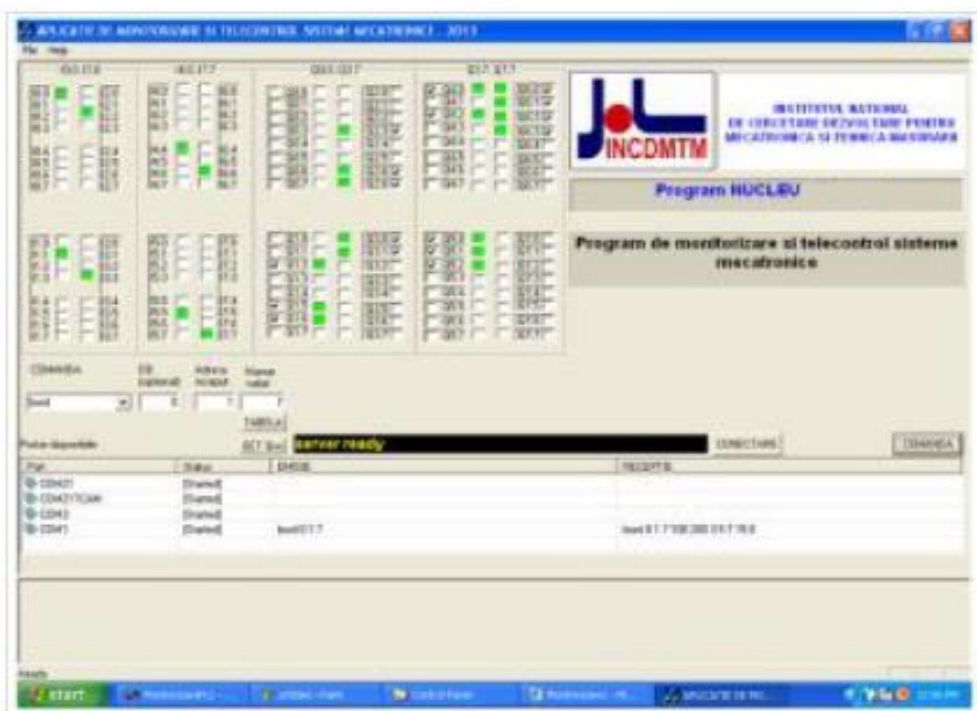

- The user interface during the entry of commands subsystem, displays the "command entry window", as follows:

$>$ Entry of command 1;

$>$ Entry of command 2;

$>$ Entry of command 3; 


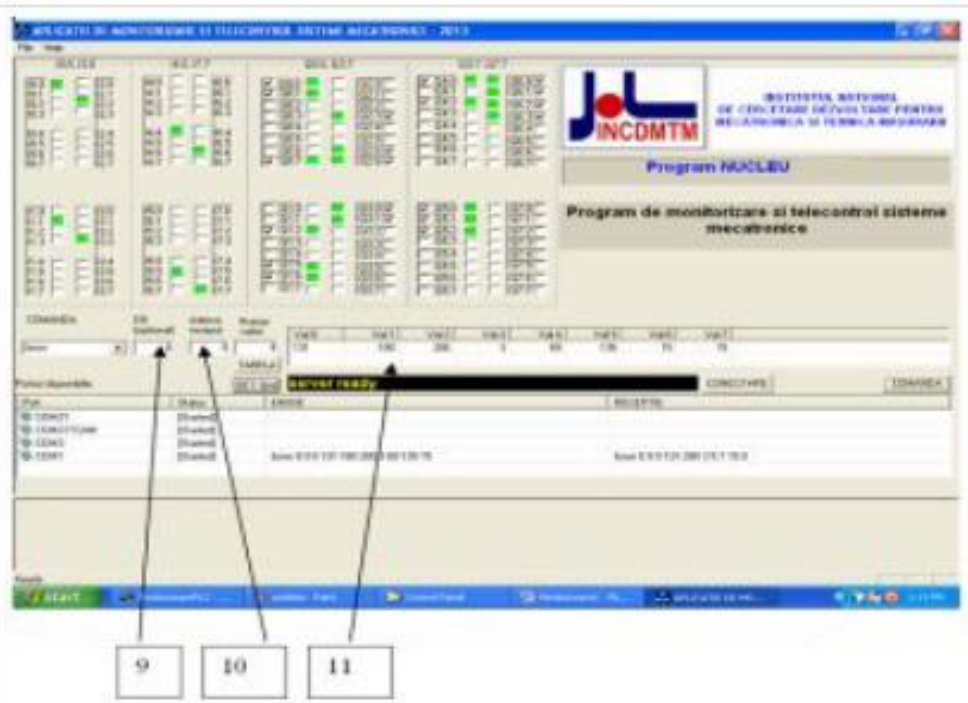

9 - Entry of command 1;

10 - Entry of command 2;

11 - Entry of command 3;

In the tests of the component subsystems and the mechatronic and adaptronic \& cyber-mecatronic and cyber-adaptronic systems, the following were used:

(a) components, subsystem and smart 4G system testing program, which includes:

(a1) methods of measurement and verification of metrological parameters present;

(a2) smart mechatronic metrological metrology systems and equipment equipped with accredited RENAR (at national level) LAMs (MEMS \& NEMS):

- OPTIMAHR - Germany, for measuring and checking dimensions, with nanometric precision ( $\leq$ $1 \mathrm{~nm})$;

- 3D precision measuring machine $(0.1 \mu \mathrm{m})$;

- Smart system with incremental rotating photoelectric transducer and digital block with digital display, in high angle and length units $(\leq \pm 1$ second);

- Tensiometric marker system with digital display for high precision forces and moments (Class 0.1 );

- High-precision digital type $(\leq 0.01 \mathrm{~mm})$;

- Analytical balance system with high precision $(\leq \pm 0.02$ grams);

- etc.

(a3) software programs for dimensional, angular measurements, etc.;

(a4) software programs for data analysis and interpretation (Siemens SIMATIC Panel PC 577 computing system, specialized software, etc.).

(b) documents in international catalogues relating to smart mechatronic systems and equipment for comparison and definition of metrological parameters (measuring range, precision, repeatability, fidelity, etc.);

(c) metrological documents such as histograms, diagrams, graphs and value matrices. For parametric and metrological tests, metrological standards corresponding to the equipment of the laboratories, ISO EN SR standards related to the measurement, verification and control methodologies and procedures were used.

5. Success indicators includes: the highprecision physical execution of components, parts, subsystems, structural systems and the experimental model assembly for the mechatronic and adaptronic and cyber-mecatronic and cyber-adaptronic systems and the testing of metrological parameters and the operation of the subsystem and the experimental model assembly, in INCDMTM metrology laboratories with RENAR certificates.

The executed structures allowed the execution and testing of the 4D mecatronic and adaptronic and cyber-mecatronic and cyber-adaptronic smart 4D mecatronic experimental model with a miniaturized, fully automated and cybernetics structure with broad applicability in various smart industrial environments such as the automotive industry electronics and mechatronics, aerospace, etc.

The realization and testing of the 4D Smart Model Experimental Model ensures the follow-up of the project, namely:

- dissemination of new knowledge and information on the project and the experimental mecatronic and adaptronic and cyber-mecatronic and cyber-adaptronic model;

- experimental model preparation for demonstration at the beneficiary;

The realization and testing of the 4D Smart Model Experimental Model represents for INCDMTM, but also for the Romanian Research System, the development of new automated and cybernetic smart products on scientific and academic 
levels first approached in Romania in original solutions and concepts and products high competitiveness.

\section{References:}

[1] "Studiu și analiză privind concepțiile modelelor virtuale mecatronice și adaptronice și cybermecatronice și cyber-adaptronice" - Gh. I. Gheorghe, 2016, Editura CEFIN;

[2]"Elaborare noi concepte ştiinţifice şi tehnologice şi noi modele virtuale mecatronice şi adaptronice şi cyber-mecatronice și cyber-adaptronice" - Gh. I. Gheorghe, 2016, Editura CEFIN;

[3] R. H. Bishop: The Mechatronics Handbook, The University of Texas at Austin, Austin, Texas, 2002;

[4] F. W. Bruns, H. H. Erbe, M. Faust: Engineering Future Laboratories, In: Marvel - A Leonardo da Vinci Pilot Project- Mechatronics Training in Real and Virtual Environments, Bremen, 2005;

[5] C. E. Pereira, S. Paladini, F. M. Schaf: Control and Automation Engineering Education: Combinig Physical, Remote and Virtual Labs, Proceedings of the 9th International Multi-Conference on Systems, Signals and Devices - SSD 2012, Chemnits, Germany, 20-23 March, pp. 1-10, 2012;

[6] I. G. Pop, V. Matiec: Transdisciplinary Approach of the Mechatronics in the Knowledge-based Society, Advances in Mechatronics, H. MartinezAlfaro (Ed.), InTech, 2011;

[7] L. Cheded, M. Al-Mulla: Control of a Four-Level Elevator System Using a Programmable Logic Controller, International Journal of Electrical Engineering Education, Vol. 39, No. 2, pp. 110117, 2002;

[8] Z. Zhang, and M. Tausner, Markov process modeling and simulation for wireless sensor network life estimation with QoS constraints, in Proceeding of 2010 Summer Computer Simulation Conference, Ottawa, Ontario, Canada, July, 2010;

[9] XBow Inc. MICA Wireless Measurement System, http://www.xbow.com/Products/. March 18, 2005;
[10] H. Zhang and J. C. Hou, Maximizing a Lifetime for wireless sensor networks, International Journal of Sensor Networks, 1, 64-71, 2006;

[11] X. Zhang, X. Chen, W. W. Hui, J. Y. Hai, V. Lantz, and K. W. Qiao. 2009. Hand gesture recogniาtion and virtual game control based on 3D Accelerometer and EMG sensors. In Proceedings of the 13th International Conference on Smart User Interfaces Canary Islands, Spain-January 13-16, 2008, pp. 401406;

[12] B. D. Noble and J. Flinn. 2007. Wireless, selforganizing cyber-physical systems. NSF Workshop on Cyber-Physical Systems. Austin, TX.

[13] H. Gharavi, K. V. Prasad, and P. Ioannou. 2007. Scanning advanced automobile technology. Proc. IEEE, 95, 328-333.

[14] H. Zhang. Overview of wireless cyber-physical systems (WCPS). [online]. Available at http://www.cs.wayne.edu/hzhang/courses/82 60/Lectures/.

[15] Bowles, P., Tiller, M., Elmqvist H., Brück D., Mattsson S.E., Möller A., Olsson A., Otter, M.: Feasibility of Detailed Vehicle Modeling. SAE World Congress, paper 01P-321, Detroit, 2001;

[16] Bunus P, Engelson V, Fritzson P, Mechanical Models Translation, Simulation and Visualization in Modelica, pp 199-208, Proceedings of the 2nd International Modelica Conference, DLR, 2002;

[17] MATLAB, SIMULINK, STATEFLOW, Real Time Workshop, http://www.mathworks.com/

[18] Busse, M.; Wostmann, F.-J.: Smart Cast Parts Application of Adaptronic Components with Cast Parts. Proc. Adaptronic Congress, Gottingen (May 2006)

[19] Development and Wirl Tower Test of the SMART Active Flap Rotor. Smart Structures and Materials 2004: Industrial Commercial Applications of Smart Structures Technologies, Eric H.Anderson (Ed.), Proc. SPIE Vol. 5388 (2004), pp.2202-212;

[20] Gheorghe I., Gheorghe, Adaptronica sistemelor inteligente, ISBN: 978-973-720-509-4, Editura CEFIN, 2014;

[21] Gheorghe I., Gheorghe, Micro-nano-ingineria inteligentă integronică, ISBN: 978-973-720538-4, Editura CEFIN, 2014. 